\title{
doispontos:
}

\section{Marx, Habermas e os novos sentidos das lutas pela emancipação da dominação}

\author{
Rúrion Melo \\ rurionmelo@gmail.com \\ Departamento de Ciência Política, Universidade de São Paulo (USP), São Paulo, SP, Brasil
}

\begin{abstract}
Resumo: O presente artigo analisa como Jürgen Habermas, ao debater com a obra de Karl Marx, procura enriquecer o conceito de práxis para além de um modelo de ação baseado unicamente no trabalho ou na atividade produtiva. Com isso, pretendemos ressaltar as consequências que essa teoria ampliada da práxis social tem para um renovado diagnóstico das lutas emancipatórias no presente e da gramática dos conflitos sociais. Um conceito renovado de práxis social, isto é, uma reconstrução dos próprios conceitos fundamentais do materialismo histórico a partir de uma outra "teoria da ação", permitiria à teoria crítica entender de que modo os novos movimentos sociais vieram desfazer, eles mesmos, a imagem produtivista de sociedade, propondo, simultaneamente, novos sentidos para as lutas emancipatórias contra formas diferenciadas de dominação.
\end{abstract}

Palavras-chave: Teoria crítica; Emancipação; Dominação social; Democracia radical; Novos movimentos sociais.

\section{Marx, Habermas and the new meanings for the emancipatory struggles against forms of domination}

Abstract:This paper analyzes how Jürgen Habermas, in debating with Karl Marx, seeks to enrich the concept of praxis beyond a model of action based solely on labor or productive activity. We intend to highlight the consequences of this expanded theory of social praxis on a renewed diagnosis of emancipatory struggles in the present and of the grammar of social conflicts. A renewed concept of social praxis, i.e., a reconstruction of the fundamental concepts of historical materialism from another "theory of action", would allow the critical theory to understand that the new social movements themselves dissolved the productivist image of society, suggesting possible new meanings for the emancipatory struggles against differentiated forms of domination.

Keywords: critical theory, emancipation, social domination, radical democracy, new social movements.

Não é possível refazer o percurso da história da teoria crítica sem compreender sua dívida com a obra de $\operatorname{Marx}^{1}$. Qualquer um dos nomes mais importantes que compõem esta tradição de pensamento - de Max Horkheimer até seus mais recentes representantes - mostraram que o confronto crítico com a teoria de Marx acompanha necessariamente toda renovação de seus diagnósticos de época bem como de seus conceitos centrais. O jargão "com Marx contra Marx” continua presente em praticamente todos os seus mais diversos representantes. Mas este jargão guarda nuances decisivas para a compreensão das muitas recepções de sua teoria. Tais recepções nunca são desinteressadas. Elas são motivadas tanto por questões históricas e políticas desafiadoras quanto por necessidade de adequação teórica. $\mathrm{O}$ que se evidencia, no entanto, é o caráter não dogmático do reconhecimento da força de sua teoria.

As "atualidades de Marx" ${ }^{2}$ são avaliadas em confronto direto com diagnósticos de época em disputa, seja com novas análises a respeito do capitalismo ou com as lutas sociais e políticas hoje manifestas. 
Tal confronto, por sua vez, suscita um acerto de contas no quadro conceitual. Este modo de proceder, na verdade, ocorre também com outros nomes importantes da teoria crítica, permitindo-nos caracterizar sua própria história de desenvolvimento como aquela baseada em uma recepção que podemos qualificar de crítica. Falar então em uma "história crítica da recepção" significa entender que Marx, Horkheimer, Theodor Adorno, Jürgen Habermas ou mesmo Axel Honneth se encontram sob o escrutínio crítico da recepção, uma vez estejamos não somente reconstruindo a própria história da teoria crítica, mas também a renovando com a finalidade de produzir diagnósticos atualizados do tempo presente. Em outras palavras, as diferentes recepções e interpretações que os teóricos críticos fazem dos autores que constituíram sua tradição intelectual são parte intrínseca do objetivo de apreender criticamente a realidade concreta da sociedade atual em suas múltiplas dimensões.

No presente artigo, limitar-me-ei tão somente à recepção de Marx na teoria de Habermas. Porém, considerando a amplitude com que Habermas revisitou a obra de Marx $x^{3}$, pretendo me concentrar nas consequências da renovação habermasiana do conceito de práxis social para os diagnósticos políticos do presente. Inicialmente, mostrarei como Habermas procura enriquecer o conceito de práxis para além de um modelo de ação baseado unicamente no trabalho ou na atividade produtiva (I). Meu intuito, no entanto, consiste em ressaltar as consequências que essa teoria ampliada da práxis social terá em relação a um também renovado diagnóstico das lutas emancipatórias no presente: não se trata de excluir a dimensão das lutas e da organização política dos trabalhadores, mas antes de reavaliar a possibilidade de reduzir as novas reivindicações à lógica do trabalho, em reduzir toda a gramática dos conflitos sociais em sua totalidade à dialética do trabalho. Um conceito renovado de práxis social, isto é, uma reconstrução dos próprios conceitos fundamentais do materialismo histórico a partir de uma outra "teoria da ação", permitiria à teoria crítica entender de que modo os novos movimentos sociais eles mesmos vieram desfazer a imagem produtivista e cristalizada de sociedade, propondo simultaneamente novos sentidos para as lutas emancipatórias (II).

A história da teoria crítica, desde sua primeira geração, está marcada pela centralidade que os conceitos de trabalho e de atividade produtiva assumiram em Marx e na tradição crítica ${ }^{4}$. Toda práxis social foi pensada como uma forma de atividade produtiva, seja em seu sentido negativo (trabalho abstrato, reificado, heterônomo) ou positivo (uma autoatividade produtiva, emancipada, trabalho autônomo). Essa concepção de práxis influenciou o imaginário político da esquerda em sua quase totalidade a tal ponto que os diagnósticos de "revolucionários" tanto quanto de "reformistas" partiram do fato inquestionável de que a sociedade capitalista podia ser explicada segundo o critério unitário dos processos de trabalho (MELO, 2012, 2013). O diagnóstico crítico que se produzia dessa centralidade do trabalho, e que se tornou paradigmático em termos teóricos com o livro de Georg Lukács (2003), apoiou-se na análise de que a "forma mercadoria" generalizaria de maneira reificante sua própria lógica sobre todas as esferas da vida social, constituindo assim um centro de dominação a ser combatido pela teoria crítica e pela práxis política.

Além disso, o próprio prognóstico relacionado às possibilidades de emancipação dessa forma de dominação replicava o horizonte produtivista, pois a perspectiva emancipatória, inteiramente voltada à superação das condições sociais do trabalho heterônomo, referia-se ao desenvolvimento das forças produtivas, à reapropriação coletiva da produção, à imagem de uma comunidade de cooperação baseada na divisão igualitária do trabalho - a famosa "associação de homens livres" (MARX, 1998). Ou seja, a libertação do trabalho heterônomo projetava uma forma de práxis social circunscrita a uma atividade produtiva autônoma, a possibilidade de que os homens voltassem a produzir de fato seu próprio mundo com consciência e vontade. De Marx ao Horkheimer da década de 1930 (HORKHEIMER, 2009), a teoria 
crítica não somente denunciou a contradição de um mundo produzido pelo capital, mas entendeu que a emancipação da dominação capitalista residia na própria práxis produtiva. ${ }^{5}$

O primeiro a tomar consciência de maneira explícita dos desdobramentos do paradigma da produção para a possibilidade de continuidade da tradição crítica e para a renovação de diagnósticos de época foi Habermas. Para tanto, ele precisou rever de maneira radical a centralidade do trabalho como uma espécie de matriz unitária de racionalidade, de onde decorreriam as expressões da dominação social e de sua própria emancipação. Mais radicalmente do que qualquer outro dos autores da primeira geração, Habermas procurou deslocar a centralidade da lógica do capital, forçando a teoria a formular uma concepção mais ampla e enriquecida de ação social. Pois sem relacionar adequadamente teoria e práxis não seria possível elaborar um diagnóstico acerca das lutas e conflitos sociais e entender o que havia se alterado em relação à centralidade da perspectiva proletária. $\mathrm{O}$ diagnóstico das lutas e dominações no presente implicava um acerto de contas com o conceito de trabalho e com os principais referenciais teóricos do materialismo histórico. Habermas atribuiu menos peso para a análise das forças produtivas e da técnica do que para a reconstrução de estruturas normativas da modernidade e seus respectivos conflitos políticos pós-liberais. Como então superar o conceito de ação social baseado no trabalho como matriz unitária de racionalidade?

Ora, desde os Manuscritos de 1844 até sua obra madura, o trabalho representou para Marx o traço mais característico da espécie humana: "o trabalho", afirma ele no Capital, "é primeiramente um processo entre homem e natureza, um processo por meio do qual o homem pode mediar, regular e controlar seu metabolismo com a natureza por meio de sua própria atividade. Ele se coloca diante dos próprios elementos naturais como produto. Ele emprega as forças naturais de seu próprio corpo, braços e pernas, cabeça e mãos, para se apropriar dos elementos naturais de uma forma útil para sua própria vida” (MARX, 1998, p. 192). Essa atividade primordial, que se inicia, segundo Marx, como um processo em que "o homem regula e controla seu intercâmbio com a natureza por meio de sua própria ação", configura o trabalho desde o início como "atividade com respeito a um fim" e que precisa incluir ainda "seu objeto e seu meio" (Idem, p. 193). Habermas encontra nessa própria interpretação de Marx da atividade com respeito a um fim a característica principal do processo do trabalho para a espécie humana como reprodução da vida material segundo regras da ação instrumental: nesse caso, a atividade instrumental dos indivíduos estaria organizada, basicamente, para os fins da produção. Além disso, também as regras da ação estratégica guiariam a coordenação social que seria um pressuposto fundamental do processo do trabalho. Nesse sentido, a distribuição dos produtos do trabalho seria socialmente organizada por meio de uma conexão sistemática de "expectativas ou interesses recíprocos" (HABERMAS, 1976, p. 146), a qual ocorreria, segundo Habermas, por meio de normas sociais de organização coletiva. Essa relação social primária que regula o trabalho e a distribuição de seus produtos consistiria na forma econômica de reprodução da vida que Marx adotaria como a mais fundamental para o desenvolvimento da história da humanidade em seu conjunto ${ }^{6}$. Ambas as formas de produção e de cooperação estariam estabelecidas sobre uma dimensão ainda reflexiva muito estreita para a reprodução histórica da vida humana, predominantemente centrada no trabalho.

Habermas não conclui dessa relação entre homem e ambiente no processo do trabalho socialmente organizado que a suposta dimensão reflexiva que o articula se estenda decisivamente para além da "transformação do material orientada por um fim segundo regras da ação instrumental" (HABERMAS, 1976, p. 145). A ação baseada no trabalho consistiria antes na autodeterminação posta no produto que constitui o processo do trabalho como autoatividade de um sujeito que controla a natureza a partir de sua própria ação, isto é, como atividade com respeito a um fim. Nessa perspectiva, o mecanismo de desenvolvimento da história da humanidade estaria limitado à ação racional com respeito a fins: com base na atividade produtiva e na cooperação social, a ação instrumental estaria diretamente imbricada pela ação 
estratégica na reprodução da vida humana. No interior da filosofia moderna, Marx deslocaria a dimensão reflexiva do modelo de um sujeito cognoscente para a práxis de um sujeito produtor como consequência do desenvolvimento das forças produtivas. Se naquele modelo as relações entre sujeito e objeto estavam fundadas em pretensões de validade assertivas, em que as opiniões sobre o mundo objetivo podem ser suscetíveis de ser verdadeiras, Marx desloca essa relação para a filosofia da práxis, sem alterar, acredita Habermas, o modelo do sujeito-objeto: a filosofia da práxis, que privilegia a relação entre sujeito agente e o mundo dos objetos manipuláveis, concebe o processo de formação da espécie (segundo o modelo da autoexteriorização) como autoprodução. Considera não a consciência de si, mas o trabalho como princípio da modernidade.

Apoiando-se nos estudos antropológicos de Arnold Gehlen sobre a técnica, Habermas contrapôs à explicação produtivista o fato de que não apenas os homens, mas também os hominídeos se distinguiriam de outros animais por se reproduzir por meio do trabalho social e de uma economia (HABERMAS, 1976, p. 148-149). O conceito de trabalho social seria fundamental porque, tal como o entende Habermas, a organização do trabalho e da distribuição precederia a emergência de relações simbólicas e reflexivas, que ocorreriam posteriormente pelas formas linguísticas de comunicação. Mas o modo de vida especificamente humano teria de ser adequadamente caracterizado somente se acrescentássemos ao conceito de trabalho social alguma forma de organização coletiva regulada por determinadas regras. Em outros termos, as estruturas simbólicas que passariam a determinar os comportamentos dos indivíduos não ficariam mais atreladas àquelas do trabalho social. Segundo Habermas, essas estruturas simbólicas de interação coletiva, intersubjetiva, não poderiam mais ser reduzidas a ações instrumentais ou estratégicas. A produção e a socialização, o trabalho social e a estrutura parental, seriam assim ambos de igual importância para a reprodução da espécie humana, de modo que seria possível afirmar que trabalho e linguagem constituiriam as bases antropológicas de toda evolução social (HABERMAS, 1976, 2014c).

Com os termos do paradigma da produção não é possível expressar claramente de onde se origina a perspectiva emancipatória. Se quisermos saber como se auto-organizam os membros de uma sociedade, então temos de alterar o modo como reconstruímos os processos de interação em cada situação. Embora Marx assumisse que o desenvolvimento das sociedades teria de poder ser localizado no desencadeamento das forças produtivas, as sociedades se desenvolveriam também por meio de um processo de aprendizado que abrangeria a dimensão de uma regulação simbólica e reflexiva de interação. Diante da filosofia da práxis e de seu modelo de ação baseada no trabalho, seria necessário entender essa dimensão simbólica com uma noção alargada de ação. A primeira diferença entre uma ação não-linguística (como a atividade produtiva) e a interação consistiria no traço reflexivo desta última. Embora todas as ações possam ser apreendidas como ação com respeito a fins, tais ações, segundo a estrutura reflexiva da interação mediada pela linguagem, também não poderiam ser realizadas sem a cooperação e o assentimento livre de coerção dos participantes na interação e poderiam ser explicadas somente pelo recurso ao conceito de entendimento que habita no interior do próprio medium linguístico. Essas ações cooperativas são definidas por Habermas como processos de entendimento. Desse modo, a ação estratégica se distinguiria da ação comunicativa na medida em que a coordenação social não estivesse apoiada apenas na ação com respeito a fins, mas na força racionalmente motivadora dos atos de entendimento, ou seja, em uma racionalidade que se manifesta nas condições para o acordo obtido comunicativamente (HABERMAS, 1976, 2014c).

A distinção entre ação com respeito a fins e entendimento apoia a diferenciação, fundamental para a análise de sociedades modernas, entre as formas de integração sistêmicas e simbólicas (HABERMAS, 1976; PETERS, 1993). Para Habermas, as sociedades modernas possuem uma estrutura de diferenciação complexa, contando com o mercado e o Estado como meios eficazes para implementar os fins da coordenação social. Mas, além disso, a sociedade é explicada como mundo da vida estruturado simbolicamente. Podemos 
sintetizar os componentes do mundo da vida segundo a reprodução cultural (um estoque de saber a partir do qual os participantes em interações extraem suas interpretações no momento em que se entendem sobre algo); a integração social (ordens legítimas por meio das quais os participantes em interações regulam sua pertença a grupos sociais e garantem a solidariedade); e as estruturas da personalidade (motivos e habilidades que colocam um sujeito em condições de falar e agir, bem como de assegurar sua própria identidade em processos de socialização) (HABERMAS, 1981).

O modelo do sujeito-objeto pressuposto no conceito de trabalho também circunscreve a práxis à filosofia do sujeito, limitando assim o conceito intersubjetivo de ação e de razão prática àquele de disposição. A autoprodução consistiria na intervenção imediata do sujeito em relação ao mundo objetivo por meio de um processo cíclico de exteriorização, objetivação e apropriação (LANGE, 1980, capítulos 1 e 2; BENHABIB, 1986 , p. 68 et seq). Mas não simplesmente restringindo tal processo à atividade de cada sujeito individual, mas também ao interpretar a sociedade como um macrosujeito: também a exteriorização, objetivação e apropriação consistiriam nas etapas constitutivas das determinações da comunidade de produtores associados que se libertariam das condições do trabalho heterônomo. Pois a dimensão social conflitiva não seria analisada a partir da capacidade de restituição material da autoatividade produtiva alienada (seja na forma do trabalho social e da produção cooperativa, ou simplesmente em termos de criação livre, etc). $\mathrm{O}$ ato de dispor e se reapropriar pressupõe que a ação livre se realiza plenamente sempre segundo um processo de metabolização entre sujeito e objeto (homem e natureza) ou entre sujeitos que se socializam em decorrência do trabalho social. O ponto de partida intersubjetivo acentuaria, pelo contrário, os entraves da socialização em sua dinâmica com a individualização, da negociação dos diversos interesses individuais e coletivos, das dominações socialmente constituídas em processo de interação cotidianos, da solução dos conflitos de valores e a dimensão não apenas material, mas simbólica da satisfação de necessidades plurais, da legitimidade de princípios e normas de regulação social no campo da moral e do direito, etc.

Portanto, a sociedade se constituiria não apenas pela atividade produtiva, mas também por meio da interação comunicativa, e esta não precisaria encerrar em si o trabalho, embora os indivíduos não possam existir sem trabalho, sem o qual não seria possível qualquer forma de sociedade. Todavia, não poderíamos reconhecer a esfera da interação ao lado da esfera do trabalho caso partíssemos de uma teoria social voltada exclusivamente à reprodução material, caso a sociedade fosse "entendida como a base a partir da qual deve ser determinada toda a superestrutura, inclusive e estrutura da consciência e da comunicação linguística" (TOMBERG, 2003, p. 300). Apenas poderíamos falar de uma relativa autonomia da interação diante da ação baseada no trabalho "se colocássemos de lado todo o paradigma produtivista e puséssemos no seu lugar o paradigma da comunicação" (Ibidem). Este paradigma possibilitaria recuperar a dimensão reflexiva da cooperação social, uma vez que só um processo de entendimento mútuo intersubjetivo pode levar a um acordo que é de natureza reflexiva. Apenas fundamentando a práxis social de modo a distinguir a autonomia entre reflexão e trabalho seria possível levar a termo a intenção de Marx em fundamentar uma teoria da emancipação a partir de uma distinção entre objetivação (uma práxis satisfeita que retorna a si mesma) e alienação (uma práxis fragmentada e paralisada).

É possível reconhecer que, na análise da mercadoria como força de trabalho, já estava presente de certa forma a distinção entre uma dimensão instrumental e outra supostamente reflexiva: o próprio Habermas reconhece que o processo do trabalho poderia ser simultaneamente descrito segundo as ações concretas correspondentes, assim como segundo as operações abstratas, como trabalho abstrato. A força de trabalho despendida constitui uma categoria em que os imperativos de integração sistêmica coincidem com aqueles da integração social: na qualidade de ação concreta, estaria ligada a contextos de cooperação; enquanto ação meramente operacional e abstrata, estaria ligada ao contexto funcional da empresa capitalista e do sistema 
econômico. Provavelmente a força da crítica elaborada no Capital residiria em descortinar, por meio de uma exaustiva análise, não os momentos reflexivos da integração social, mas sim aquelas operações reificantes que constituem o trabalho abstrato e que submetem as ações concretas aos imperativos sistêmicos. Porém, Marx não poderia entender a transformação do trabalho concreto em trabalho abstrato como um caso especial de uma reificação sistemicamente induzida de relações sociais, porque

parte do modelo do ator que age segundo uma racionalidade com respeito a fins, e que, ao ser despossuído de seus produtos, se vê também privado da possibilidade de desenvolver suas capacidades mais essenciais. A teoria do valor é desenvolvida segundo conceitos fundamentais da teoria da ação que tornam necessário situar a gênese da reificação por baixo do âmbito de interação e tratar a deformação das próprias relações interativas [...] como fenômenos deduzidos. (HABERMAS, 1981, vol. 2, p. 503-504)

Da mesma forma, a práxis revolucionária, cuja atividade só pode provir do trabalho, está circunscrita ao modelo do sujeito-objeto e conta tão somente com a racionalidade com respeito a fins do sujeito que age. Essa assimilação do trabalho social ao modelo da autoatividade teria, portanto, um conteúdo normativo duvidoso, permanecendo ambíguos tanto o conceito de trabalho quanto sua correspondente racionalidade com respeito a fins. No final, a práxis produtiva não ofereceria os meios para pensar o trabalho heterônomo como intersubjetividade paralisada e mediatizada, envolvendo uma sensibilidade maior da teoria para formas de dominação e práticas comunicativas cotidianas que estão na base das interações sociais e das expressões culturais da sociedade.

\section{II}

Embora por meio do trabalho os indivíduos aprendam a dominar o mundo natural e desenvolver o conhecimento instrumental e técnico, contudo, seria a interação social que denotaria a especificidade da práxis humana e fundamentaria o núcleo normativo a partir do qual a dominação social poderia ser identificada e, principalmente, contestada. Nesse sentido, a expansão das forças produtivas não deixaria de explicar somente o que concerne ao complexo desenvolvimento das capacidades intersubjetivas, uma vez que a interação seguiria seu próprio padrão evolutivo, mas também, centralizada na produção, reduziria o potencial para emancipação presente na esfera da interação. Os processos de reificação descritos na crítica social de Marx mostrariam, antes, que a dimensão do trabalho no capitalismo produziria o oposto da atividade autônoma e da emancipação, ou seja, caracterizaria tais relações de interação social como independentes da vontade dos indivíduos, cuja lógica se reproduz de acordo com os próprios imperativos que se autonomizam. Por isso, esse estreitamento do conceito de práxis significaria assim que a dimensão determinante e constitutiva da política no processo revolucionário seria enfraquecida uma vez que tal processo não poderia ser avaliado a partir da autodeterminação dos agentes, mas esta autodeterminação teria de "ser esclarecida antes a partir das contradições da vida material, dos conflitos existentes entre as forças produtivas da sociedade e as relações de produção" (MARX, 1961, p. 9). E no momento em que deduz a luta de classe da lógica de reprodução capitalista, a solução política passa a depender de um processo "que se realiza pelas costas das classes que estão em luta" (WELLMER, 1969, p. 101).

Ao crescimento das forças produtivas e à correspondente emancipação da sociedade diante das forças da natureza, por conseguinte, não corresponderia imediatamente uma diminuição da opressão social e política. Os dois desenvolvimentos não convergiriam necessariamente. Na verdade, eles seriam, em grande medida, independentes. A dialética das forças produtivas e das relações de produção não abarcaria as dimensões da emancipação da sociedade presentes em outros âmbitos da ação social ${ }^{7}$. Esse alerta remete certamente para as regiões mal iluminadas da teoria de Marx, sobretudo quando se trata de interpretar corretamente o vínculo entre forças produtivas e relações de produção para com isso evitar, seja no contexto de teorias 
tradicionais ou mesmo da própria teoria crítica, interpretações meramente funcionalistas. Os sujeitos que constituem seus próprios mundos, ou que o compartilham de forma intersubjetiva, perderiam seu lugar nos processos de integração social, isto é, as interações realizadas de forma consciente dariam lugar à mera reprodução funcional. Todos os vestígios reflexivos, nos quais uma teoria da sociedade, que parte da autocompreensão dos atores, ainda poderia encontrar acesso à sociedade, seriam apagados, e os ganhos analíticos da teoria corresponderiam a perdas para uma teoria com intenções prático-emancipatórias. A distinção entre a dimensão da ação ligada ao trabalho e aquela atrelada à ação simbólica e reflexiva seria necessária, assim, para uma compreensão da dinâmica política em que as condições da emancipação social se encontrassem em disputa na base da sociedade ${ }^{8}$.

O modelo de ação baseado no trabalho permitiu, assim, que Marx pudesse pressupor um tipo de conhecimento da totalidade - deduzido de uma concepção de sociedade moderna que se realiza fundamentalmente por meio do trabalho - que "se permite fazer laudos clínicos sobre a qualidade alienada e não-fracassada das formas de vida em seu conjunto” (HABERMAS, 1990, p. 191). Habermas, por sua vez, não pretende pensar a sociedade em uma unidade superior, tal como aconteceria na relação entre trabalho e natureza. $\mathrm{O}$ âmbito da interação simbólica não pode ser representado segundo um modelo de autoprodução nem mesmo como a autorrealização de um macrosujeito: ambos encerram um conceito de totalidade não mais adequado às diferenciações altamente complexas das sociedades modernas e nem às novas lutas e gramáticas sociais de conflito. Além disso, hipostasiaríamos também o processo de acordo e negociação intersubjetiva tal como acontece em uma concepção de práxis fundada no processo de trabalho, uma práxis pensada como uma totalidade de um sujeito de nível superior.

Se, diferentemente, atribuíssemos uma dinâmica própria à esfera da interação política, então as contradições sociais estariam vinculadas à vida material de uma outra perspectiva que não necessariamente aquela apresentada pelo paradigma produtivista: as contradições sociais seriam diagnosticadas criticamente porque estariam fundadas na discrepância entre a realização possível e a opressão factual das necessidades reais dos indivíduos, ou seja, elas só seriam contradições porque, na interpretação e legitimação de suas necessidades, os grupos sociais se colocariam em contradição com as interpretações e legitimações tradicionais que formariam as relações de dominação existente. "Mas isso significaria", afirma decisivamente Wellmer, "que as formas com que os homens tomam consciência de seus conflitos sociais e os disputam não seriam apenas epifenômenos das contradições 'objetivas' entre forças produtivas e relações de produção, mas antes seus momentos constitutivos" (WELLMER, 1969, p. 102).

A teoria crítica com intenções emancipatórias pode pretender identificar obstáculos à emancipação ou os potenciais emancipatórios presentes em determinado contexto ao manter em aberto o processo de autodeterminação. Se o conceito de emancipação tem de ser entendido como disputa, ou seja, como a luta contra a dominação em prol da autonomia na definição, interpretação e também constituição dos próprios processos sociais, não poderíamos decidir de antemão (por razões teóricas ou práticas) os rumos de um projeto político sempre inacabado. "Na melhor das hipóteses”, ressalta o próprio Habermas, "uma teoria [poderia] indicar as condições necessárias para formas de vida emancipadas, cuja configuração concreta teria de ser primeiramente decidida pelos próprios concernidos” (HABERMAS, 1990, p. 191). Não obstante possamos compreender que esse conceito de emancipação precisa ser diferentemente preenchido de sentido em suas mais variadas formas, essa relação entre trabalho e interação não está apoiada apenas nas considerações sobre uma teoria da ação mais reflexiva e alargada, isto é, um conceito de práxis social enriquecido. A reconfiguração das relações de classe no capitalismo tardio, os efeitos colaterais do poder administrativo cada vez mais intervencionista e os processos de reificação da consciência cotidiana também deslocaram o potencial dos novos conflitos sociais para a gramática plural das formas de vida. 
Os ideais que tradicionalmente inspiraram as lutas socialistas por transformação na organização social e nos arranjos institucionais não apenas esgotaram suas energias utópicas, mas se colocaram em paralelo a demandas por reconhecimento de diferenças culturais e formas descentralizadas de dominação. Essa "condição pós-socialista”, para usar um termo de Nancy Fraser, pode ser diagnosticada adequadamente apenas se a teoria crítica contemporânea repensar profundamente a relação entre teoria e prática (FRASER, 1997). O esforço de renovação de modelos críticos do presente, que não apenas resultaram da perspectiva habermasiana, mas também tentaram superar seus muitos problemas, significou antes o limite de um referencial teórico e prático que não teria força suficiente para sustentar sua perspectiva de análise social e de expectativa de transformação política sempre segundo a mesma matriz unitária e, por conseguinte, totalizante de dominação e de dominação diante de diagnósticos políticos e culturais tão modificados. Por esta razão, uma das principais tarefas da teoria crítica na "condição pós-socialista" consistiria em compreender a pluralidade de lutas sem englobá-las em algum projeto emancipatório totalizante. Esse descentramento - ou "destotalização" - do referencial estabelecido pelo paradigma produtivista pressupõe processos emancipatórios parciais de lutas pela autonomia e integridade das formas de vida e aponta para a possibilidade de superação da antinomia clássica entre reforma ou revolução ao lançar nova luz à pluralidade de sentidos que a teoria crítica atribuiria hoje aos ideais emancipatórios (COHEN, 1982; ARATO e COHEN, 1992).

É por essa razão que o acerto de contas de Habermas com o paradigma produtivista implicou reconsiderar a política, o direito e a democracia não mais como expressões meramente ideológicas, sempre sobredeterminados por recortes de classe e reduzidos a epifenômenos da economia. Interações simbolicamente mediadas permitem à teoria crítica localizar os processos de dominação e de luta no quadro das disputas políticas e jurídicas. Na verdade, vincular o propósito emancipatório da teoria com um projeto de democracia radical - envolvendo a preocupação com a legitimação democrática do sistema político, as revoltas e mobilizações dos cidadãos e uma tematização persistente dos movimentos sociais na esfera pública - passou a ser constitutivo dos diagnósticos críticos do presente (HABERMAS, 1994). Por isso, em termos teóricos, a ambiguidade do conceito marxista de trabalho decorreria das dificuldades com que pensaria as tarefas do direito e da democracia (qualidade da representação, dimensões participativas e deliberativas do processo de formação da opinião e da vontade etc.) na perspectiva plural dos movimentos sociais contemporâneos.

Pois um conceito enriquecido de práxis social nos permite especificar experiências de injustiça, sofrimento e desrespeito reproduzidas de dentro das interações sociais. Habermas consegue diluir socialmente a linguagem da justiça e do direito para o interior da sociedade, nunca a separando de expectativas emancipatórias nascidas do sofrimento pessoal, da violência cotidiana, das patologias disseminadas nos contextos sociais da vida. Tais patologias são engendradas por expressões de poder socialmente produzidas, mas que assumem aspectos diferenciados, ainda que interconectados: dominações na esfera do trabalho, nas relações íntimas, na esfera pública ligados a questões econômicas, de raça, de gênero, de exclusão política, etc. Se emancipação e dominação puderam no marxismo ser unificados pela matriz do trabalho, dificilmente hoje o esquema geral da produção serviria "como ponto de partida para unificar, teórica e praticamente, a pluralidade de lutas e movimentos sociais na sociedade contemporânea” (COHEN, 1982, p. xii). Trata-se, portanto, de repensar os pressupostos teóricos para um diagnóstico descentralizado da dominação, ou seja, sem excluir dominações não determinadas unicamente pelas relações de classe socioeconômicas, sem limitar as gramáticas dos conflitos sociais à contradição entre capital e trabalho, sem engessar outras fontes de motivação para a orientação social e lutas políticas.

Não decretamos de maneira alguma a fraqueza de Marx ou do materialismo histórico. Muito pelo contrário. Como o próprio Habermas insiste, trata-se antes de procurar seguir a atitude crítica e os interesses práticos que estavam no cerne do materialismo histórico, no esforço de dar continuidade a uma ampla e consistente 
crítica do capitalismo, dos novos sujeitos políticos e da democracia nos dias de hoje (HABERMAS, 2013a). Mas isso implica aceitar uma série de constrições metodológicas que recaem sobre todo teórico crítico que pretenda fundamentar sua crítica de modo socialmente imanente e manter uma imprescindivel relação com a práxis. $\mathrm{E}$ já que todas as relações sociais historicamente deformadas só podem ser reparadas de modo prático, aqui Habermas também revela os limites da própria teoria. Cabe à teoria crítica diagnosticar as formas de dominação e apontar, se for o caso, potenciais de luta e transformação. Isso significa que o ônus da emancipação diz respeito primordialmente aos próprios concernidos, que assumem na qualidade de participantes a resolução prática de seus conflitos nos processos políticos em que se veem enredados. A teoria crítica não deve antecipar o resultado de problemas imediatamente práticos, marcados por uma dinâmica histórica aberta, porosa e indeterminada. Por isso, o esforço em reconstruir uma teoria da ação adequada às ambiguidades e indeterminações das interações sociais e dos jogos de poder que também constituem a política e o próprio direito, sem perder de vista critérios imanentes de crítica enraizados nas experiências autônomas dos sujeitos. Nesse sentido, como procurei frisar, uma teoria crítica da política mostra seu êxito ao conseguir simultaneamente estar com e contra Marx, sem que isso implique simplesmente uma preocupação, típica de teorias tradicionais, em resguardar a integridade sistemática de sua obra ou a "verdade" de sua doutrina.

\section{NOTAS}

1. As principais reconstruções da história da teoria crítica levam em consideração o enfrentamento com o marxismo em geral e com a obra de Marx em particular. As referências bibliográficas são muitos extensas. Ressalto aqui particularmente COHEN, 1982; JAY 1994, 2008; DUBIEL, 1985; BENHABIB, 1986; FEENBERG, 2014.

2. Expressão presente em JAEGGI e LOICK, 2013. Nesta coletânea, vemos uma surpreendente diversidade de novos pontos de vista na interpretação e crítica da teoria de Marx. Os organizadores do volume insistem no tema das "atualidades" de Marx, ressaltando a pluralidade existente em sua recepção.

3. Além da assumida presença da concepção de "democracia radical" do jovem Marx na crítica de Habermas à mudança estrutural da esfera pública (HABERMAS, 2014a), e das várias versões da reconstrução do materialismo histórico, que confirmam à época o marxismo como fundamento da teoria crítica (1976, 2013a, 2013b), não devemos esquecer que o projeto de uma teoria dos interesses do conhecimento, que teria sido interrompido na década de 1970, também devia explicitamente ao paradigma da "luta de classes" (2014b). Em vários outros momentos da obra o confronto com Marx aparece de maneira mais ou menos explícita: na questão da técnica e da ciência (2014c), no debate sobre os fundamentos da teoria do valor-trabalho (1973), no diagnóstico da reificação como colonização (1981).

4. Também neste caso as referências bibliográficas são vastas. No que diz respeito à recepção específica na tradição crítica das formulações de Marx sobre trabalho e produção, cf. especialmente LANGE, 1980; ALBERS, 1975; HABERMAS, 2013a, 2013b; BERNSTEIN, 1971; FEENBERG, 2014.

5. Refiro-me aqui ao período dos anos de 1930 porque, com o diagnóstico do "capitalismo de Estado" produzido por Friedrich Pollock no início da década, marcada principalmente pela publicação de Dialética do esclarecimento, o conceito de trabalho perde definitivamente todos os seus traços de "não-dominação". Muito pelo contrário, o trabalho passa a ser visto como a forma paradigmática de dominação por excelência. O problema é que somem do horizonte emancipatório outras formas de ação que pudessem expressar uma práxis social crítica: junto com o trabalho, permanece bloqueada a relação da teoria crítica com a dimensão da práxis política e com possíveis tendências emancipatórias. Cf. ADORNO e HORKHEIMER, 1985. Sobre essa mudança de atitude diante do trabalho, ver também HONNETH, 1999; HABERMAS, 1981; FEENBERG, 2014.

6. Segundo Marx e Engels, "a produção da vida, tanto da própria vida no trabalho quanto da vida dos outros na procriação, já parece se mostrar desde logo como uma dupla relação - de um lado, como relação natural, de outro 
lado, como relação social - , social no sentido de que se entende por ela a cooperação de diversos indivíduos, não importam suas condições, modos ou fim. Segue-se disso que um determinado modo de produção ou um determinado estágio industrial estão sempre unidos a um determinado modo de cooperação ou a um determinado estágio social, e este próprio modo de cooperação é uma 'força produtiva', a soma das forças de produção acessíveis ao homem condiciona o estado social e, portanto, a 'história da humanidade' deve ser estudada e elaborada sempre em relação com a história da indústria e da troca” (ENGELS e MARX, 1990, p. 29-30).

7. Comentando tal problema, Thomas McCarthy acredita que a insistência na "heterogeneidade" ou "irredutibilidade" entre trabalho e interação consiste em negar a fusão entre techne e praxis, entre progresso técnico e conduta racional da vida, "que sabemos que se encontra nas raízes da ideologia tecnocrata. Racionalização não significa emancipação" (McCARTHY, 1985, p. 36)

8. Com essa perspectiva aberta por Habermas, não se trata de modo algum de negligenciar a dimensão econômica da reprodução social nem o papel das lutas contra injustiças materiais. Trata-se antes de superar os referenciais funcionalistas (que não estamos atribuindo a Marx, vale dizer) com alternativas para a teoria social da dominação e da emancipação. Em relação a modelos críticos atualmente em vigor, significa optar por análises diferentes daquela de POSTONE (1993), por exemplo, em que a dimensão da política e da dominação vista do ponto de vista da experiência dos sujeitos sociais está ausente, para procurar incorporar elementos gramscianos ou, mais especificamente, de ação social e de cultura política, como aqueles formulados adequadamente por THOMPSON, 1963. Sobre o papel de Habermas nessa direção bem como os limites desse empreendimento, cf. HONNETH, 1999.

\section{REFERÊNCIAS BIBLIOGRÁFICAS}

ADORNO, T. W.; HORKHEIMER, M. 1985. Dialética do esclarecimento. Rio de Janeiro: Jorge Zahar.

ALBERS, F- J. 1975. Zum Begriff des Produzierens im Denken von Karl Marx. Meisenheim am Glan: Anton Hain.

ARATO, A.; COHEN, J. 1992. Civil society and political theory. Massachusetts: MIT.

BENHABIB, S. 1986. Critique, Norm and Utopia: A Study of the Foundations of Critical Theory. New York: Columbia University Press.

BERNSTEIN, R. 1971. Praxis and Action. Philadelphia: University of Philadelphia Press.

COHEN, J. 1982. Class and Civil Society: The Limits of Marxian Critical Theory. Massachusetts: MIT.

DUBIEL, H. 1985. Theory and Politics: Studies in the Development of Critical Theory. Cambridge: MIT Press.

ENGELS, F.; MARX, K. 1990. Deutsche Ideologie. In: Marx-Engels Werke. Band 3. Berlin: Dietz Verlag.

FEENBERG, A. 2014. The Philosophy of Praxis: Marx, Lukács and the Frankfurt School. London/New York: Verso.

FRASER, N. 1997. Justice Interruptus: Critical Reflections on the "Postsocialist" Condition. New York/London: Routledge.

HABERMAS, J. 1973. Legitimationsprobleme im Spätkapitalismus. Frankfurt am Main: Suhrkamp. 
. 1976. Zur Rekonstruktion des Historischen Materialismus. Frankfurt am Main: Suhrkamp.

. 1981. Theorie des kommunikativen Handelns. 2 Bände. Frankfurt am Main: Suhrkamp.

. 1990. Die nachholende Revolution und linker Revisionsbedarf: Was heißt Sozialismus heute?.

In: HABERMAS, J. Die nachholende Revolution. Frankfurt am Main: Suhrkamp.

. 1994. Faktizität und Geltung. Frankfurt am Main: Suhrkamp.

2013a. Entre filosofia e ciência: Marxismo como crítica. In: HABERMAS, J. Teoria e práxis. São Paulo: Unesp.

.2013b. Adendo - Recensão bibliográfica sobre a discussão filosófica em torno de Marx e do marxismo. In: HABERMAS, J. Teoria e práxis. São Paulo: Unesp.

.2014a. Mudança estrutural da esfera pública. São Paulo: Unesp.

.2014b. Conhecimento e interesse. São Paulo: Unesp.

.2014c. Técnica e ciência como "ideologia". São Paulo: Unesp.

HONNETH, A. 1999. Teoria crítica. In: GIDDENS, A.; TURNER, J. (eds.). Teoria social hoje. São Paulo: Unesp.

HORKHEIMER, M. 2009. Traditionelle und kritische Theorie. In: Gesammelte Schriften. Band 4. Frankfurt am Main: Fischer.

JAEGGI, R.; LOICK, D. (eds.). 2013. Nach Marx: Philosophie, Kritik, Praxis. Berlin: Suhrkamp.

JAY, M. 1984. Marxism and Totality. Berkeley: University of California Press.

.2008. A imaginação dialética: História da Escola de Frankfurt e do Instituto de Pesquisas Sociais (1923-1950). Rio de Janeiro: Contraponto.

LANGE, E. M. 1980. Das Prinzip Arbeit. Frankfurt am Main: Ullstein.

LUKÁCS, G. 2003. História e consciência de classe. São Paulo: Martins Fontes.

MCCARTHY, T. 1985. The critical theory from Jürgen Habermas. Massachssets Institute of Technology.

MARX, K. 1961. Zur Kritik der Politischen Ökonomie. In: Marx-Engels Werke. Band 13. Berlin: Dietz Verlag. 1998. Das Kapital. Vol 1. In: Marx-Engels Werke. Band 23. Berlin: Dietz Verlag.

MELO, R. 2012. Habermas et la nécessaire révision de la gauche. Rue Descartes, 76.

2013. Marx e Habermas: Teoria crítica e os sentidos da emancipação. São Paulo: Saraiva.

PETERS, B. 1993. Die Integration moderner Geselschaften. Frankfurt/M, Suhrkamp. 
POSTONE, M. 1993. Time, Labor, and Social Domination. Cambridge University Press.

THOMPSON, E. P. 1963. The Making of the English Working Class. New York: Vintage Books.

TOMBERG, F. 2003. Habermas und der Marxismus. Wüzburg: Königshausen \& Neumann.

WELLMER, A. 1969. Kritische Gesellschaftstheorie und Positivismus. Frankfurt am Main: Suhrkamp. 